\title{
Shifts in Microbial Community and Its Correlation with Degradative Efficiency in a Wastewater Treatment Plant
}

\author{
Atya Kapley ${ }^{1} \cdot$ Ruyin Liu ${ }^{2} \cdot$ Niti B Jadeja ${ }^{1}$. \\ Yu Zhang ${ }^{2} \cdot$ Min Yang ${ }^{2} \cdot$ Hemant J Purohit ${ }^{1}$
}

Received: 25 March 2015 / Accepted: 1 June 2015/

Published online: 12 June 2015

(C) Springer Science+Business Media New York 2015

\begin{abstract}
A wastewater treatment plant controls the level of pollution reaching the environment. Yet, despite being the most common aerobic route for treatment of wastewater, the activated sludge process is not utilized to its full potential. This is mainly due to the lack of knowledge base correlating the microbial community in the activated sludge to its degradative performance. In this study, the activated biomass at the treatment site was monitored for five consecutive months. Even though operational parameters were kept constant, the microbial community was observed to change after 3 months. This shift was seen to correlate with $25 \%$ loss of degradative efficiency. Target oxygenases were monitored at two time points, and results indicated that the dominating pathway operating in the common effluent treatment plant (CETP) is the degradation of chlorinated aromatics. This study demonstrates the change in degradative efficiency in a CETP with the change in microbial community and analyzes the parameters influencing the microbial community of activated sludge.
\end{abstract}

Keywords Activated sludge - Density gradient gel electrophoresis (DGGE) - Genomic tools · Oxygenases

Electronic supplementary material The online version of this article (doi:10.1007/s12010-015-1703-2) contains supplementary material, which is available to authorized users.

Atya Kapley

a_kapley@neeri.res.in

1 Environmental Genomics Division, National Environmental Engineering Research Institute - CSIR, Nehru Marg, Nagpur 440020, India

2 State Key Lab. of Environmental Aquatic Chemistry, Research Center for Eco-Environmental Sciences, Chinese Academy of Sciences, P. O. Box 2871, Beijing 100085, China 


\section{Introduction}

As environmental pollution levels increase, it becomes more crucial to manage pollutants reaching the environment. Wastewater treatment plants play a key role in managing domestic and industrial waste [1]. The most common aerobic route used in the cleanup of wastewater, is the activated sludge process (ASP), wherein the microbial population residing in the activated sludge is responsible for degradation of pollutants in the wastewater. Industrial wastewaters present a greater challenge to the microbial community, not only do they contain a diverse array of xenobiotics, but in most cases, the composition of the wastewater changes with the production schedule causing changes in the microbial community profile. These problems are compounded in the common effluent treatment plant (CETP), where the wastewater from several industrial units is pooled before treatment [2]. Sometimes, the cost of wastewater treatment could shift the economics of small-scale industries, making treatment a nonviable option. To help such industries, the concept of the common effluent treatment process was formulated. A CETP is a wastewater treatment facility that is especially designed to treat the effluent originating from a cluster(s) of small-scale industries (SSIs) [3]. Wastewater from all these SSIs is transported to a common treatment plant where it is pooled and treated before it can be released into the environment. The common infrastructure reduces the treatment cost to be borne by an individual member unit to a minimum, while protecting the environment to a maximum. In India, small-scale industries, majorly comprise of fine chemicals, dyes and dye intermediates, bulk drugs, and pharmaceuticals. Member industries contributing wastewater to a CETP could be anywhere between the range of 80-500 SSIs per treatment plant. In China, a centralized wastewater treatment (CWWT) facility was demonstrated at a pharmaceutical industrial park that operated at low cost but high efficiency [4]. This concept has also been reported in Malaysia [5], Turkey [6], and Arab region [7], where combined treatment helps in lowering treatment cost, encouraging SSIs to treat their wastewater before releasing it into the environment.

The operational procedure is largely uniform for these setups. Wastewaters generated at different industries are released as per the pretreatment guidelines and transported to the CETP via tankers or pipelines. The operational step at CETP starts with physicochemical treatment by removal of suspended solids and colloidal material. This is followed by collection and holding the wastewater at an equalization tank in order to reduce the possible shock loadings entering in to biological reactors. The wastewater is then channeled into the aerated biological unit containing the activated sludge (retention time varies for different CETPs) with calculated nitrogen and phosphate as additional nutrients. From there, the wastewater goes into a clarifier where the sludge is settled and finally recirculated into the ASP and the treated wastewater is released into the environment with polishing treatment, if required.

Even though such systems are operational, they are not utilized to their full potential for a variety of reasons. The major reason is that the microbial potential in the activated sludge is a black box that has not been fully explored and understood. The bottle neck used to be the lack of knowledge about the microbes involved in the pollutant cleanup process [8]. However, today, this no longer holds true. The last decade saw a number of reports where genomic tools have been used to study the microbial diversity of such niches [1, 2, 9-12]. But is knowledge of taxonomy alone enough to improve efficiency of a treatment plant? While taxonomic knowledge is important, it is also very essential to understand the parameters influencing the catabolic capacity of the bacterial community in activated sludge. Metagenomic tools can reveal the black box of activated sludge, but these techniques cannot be used timely to reveal 
the dynamics of the microbial community in response to the changes of wastewater compositions. A simple tool available for the operators is required to record dynamics of the microbial compositions in correlation to CETP performance, which is important in diagnosing the problems of CETPs. Then, the knowledge may be used to assist the management of CETPs, by implementing bioaugmentation, or adding minimal chemicals to induce the expression of some key enzymes.

This study demonstrates how the change in microbial community affects the degradative capacity of the treatment plant. The model niche used here was a CETP in South India. The treatment plant was monitored for five consecutive months and the parameters being operated at the CETP were analyzed, and their role in maintaining the microbial population was discussed. By employing some simple techniques like random amplified polymorphic DNA (RAPD) and density gradient gel electrophoresis (DGGE), this study reveals the correlation between microbial community compositions and CETP performance. Functional genes encoding key aromatic degradation enzymes were analyzed for the assistance to understand the reason for the deterioration of CETP performance. The importance of monitoring the biological parameters is also discussed.

\section{Materials and Methods}

\section{Collection of Activated Biomass}

Activated biomass was collected from a CETP in South India, treating wastewaters generated by over 100 small-scale industries including, chemical and drug industries, plastics, paints and polymers, mechanical and allied industries, food and allied, mineral based, etc. The CETP runs at a capacity $2000-2500 \mathrm{~m}^{3} /$ day. Activated biomass samples were collected for 5 consecutive months (August-December) and will be referred to as samples 1 to 5. Biomass was collected from the activated sludge unit from nine different points and pooled to represent a homogeneous sample, as described earlier [13]. The pooled biomass was allowed to stand for $10 \mathrm{~min}$ for settling. One-liter settled biomass was collected in a 5-L collection bottle and layered with $1 \mathrm{~L}$ of wastewater from the ETP and brought to the laboratory on ice within $24 \mathrm{~h}$.

\section{Operational Parameters Maintained at the CETP Treatment Site}

The operational parameters being maintained and monitored on-site are listed in Table 1. They include hydraulic retention time (HRT), mixed liquor suspended solids (MLSS), mixed liquor volatile suspended solids (MLVSS), food to mass ratio (F/M), and the chemical oxygen demand (COD). The COD is a measures the amount of organic compounds in water. For this reason, the efficiency of degradation at the CETP is assessed by its COD levels.

\section{Analyzing the Microbial Community of the CETP}

Metagenome of the activated sludge was prepared from all five sampling time points described above as per a previously published protocol [14]. This protocol uses organic solvent extraction with mild detergent treatment to remove various organics from the sample. DNA was prepared from $100 \mathrm{mg}$ sludge (five replicates and pooled) and stored at $-20{ }^{\circ} \mathrm{C}$ until required. DNA prepared was analyzed using the following tools. The bacterial taxonomy at 
Table 1 Operational parameters of the activated sludge process (ASP) maintained at the treatment plant facility

\begin{tabular}{lllllllll}
\hline Month & $\begin{array}{l}\text { HRT } \\
(\text { days })\end{array}$ & $\begin{array}{l}\text { MLSS } \\
(\mathrm{mg} / \mathrm{L})\end{array}$ & $\begin{array}{l}\text { MLVSS } \\
(\mathrm{mg} / \mathrm{L})\end{array}$ & $\begin{array}{l}\text { \% VSS of } \\
\text { MLSS }\end{array}$ & $\begin{array}{l}\text { Flow }\left(\mathrm{m}^{3} /\right. \\
\text { day })\end{array}$ & $\begin{array}{l}\text { Volume of } \\
\text { ASP }\left(\mathrm{m}^{3}\right)\end{array}$ & $\begin{array}{l}\text { F/M per } \\
\text { day }\end{array}$ & $\begin{array}{l}\text { COD } \\
\text { removal }\end{array}$ \\
\hline 1. & 6.42 & 4228 & 3074 & 73 & 2532 & 16,250 & 0.101 & 81 \\
2. & 6.43 & 3994 & 2994 & 75 & 2526 & 16,250 & 0.107 & 82 \\
3. & 7.69 & 4003 & 2990 & 75 & 2112 & 16,250 & 0.094 & 81 \\
4. & 7.55 & 3293 & 2352 & 71 & 2151 & 16,250 & 0.125 & 78 \\
5. & 7.83 & 3306 & 2680 & 81 & 2075 & 16,250 & 0.105 & 55 \\
\hline
\end{tabular}

HRT hydraulic retention time, MLSS mixed liquor suspended solids, MLVSS mixed liquor volatile suspended solids, $F / M$ food to microorganisms ratio, $C O D$ chemical oxygen demand; a measure of the organic loading in the wastewater

time point 1 was analyzed using both culture-dependent and culture-independent tools as described earlier [2].

\section{RAPD Analysis}

RAPD was carried out in a Perkin Elmer 9600 DNA thermal cycler using primer 5'd[CCCG TCAGCA] 3' as reported earlier [14]. Thermocycling conditions used were as follows: $95^{\circ} \mathrm{C}$ for $1 \mathrm{~min}$ followed by 40 cycles of $94{ }^{\circ} \mathrm{C}$ for $1 \mathrm{~min}, 50{ }^{\circ} \mathrm{C}$ for $1 \mathrm{~min}$ and $72{ }^{\circ} \mathrm{C}$ for $2 \mathrm{~min}$. The reaction mix contained $100 \mathrm{ng}$ DNA in $1 \times$ PCR buffer, $200 \mu \mathrm{M}$ each of dNTPs, $3 \mathrm{mM} \mathrm{MgCl}_{2}$, 25 pmol of primer, and 2.5 units of Taq DNA polymerase (Applied Biosystems, USA) in a final volume of $50 \mu \mathrm{l}$.

\section{Analysis of the Microbial Community Using DGGE}

The bacterial community in activated sludge was monitored by DGGE as described by Muyzer et al. [15]. The primers used in this study are listed in Table 2. In order to minimize PCR bias in PCR-DGGE, three separate reactions were run for each sample and the results were pooled. Touchdown PCR was employed as follows: $95^{\circ} \mathrm{C}$ for $10 \mathrm{~min}$, followed by 20 cycles of $95^{\circ} \mathrm{C}$ for $1 \mathrm{~min}, 65^{\circ} \mathrm{C}$ (reduced by $0.5^{\circ} \mathrm{C}$ each cycle) for $45 \mathrm{~s}$, and $72{ }^{\circ} \mathrm{C}$ for $1 \mathrm{~min}, 10$ cycles of $95^{\circ} \mathrm{C}$ for $1 \mathrm{~min}, 55^{\circ} \mathrm{C}$ for $45 \mathrm{~s}$, and $72{ }^{\circ} \mathrm{C}$ for $1 \mathrm{~min}$, and a final extension at $72{ }^{\circ} \mathrm{C}$ for $5 \mathrm{~min}$. The resulting amplification products were separated using DGGE with the Dcode Universal Mutation System (Bio-Rad, Hercules, CA, USA). The PCR products $(20-25 \mu \mathrm{l})$ were loaded onto $6 \%(w / v)$ polyacrylamide gels in Tris-acetate-EDTA buffer (pH 7.4). The gels had denaturing gradients of $35-57 \%$ (100\% denaturant contains $7 \mathrm{M}$ urea and $40 \%$ formamide) and were run at $150 \mathrm{~V}$ at $60{ }^{\circ} \mathrm{C}$ for $4.5 \mathrm{~h}$. After electrophoresis, the gels were stained for $15 \mathrm{~min}$ with ethidium bromide and photographed on a UV transillumination table using a Gel Documentation System (Bio-Rad Laboratories-Segrate, Milan, Italy). DGGE gels were processed using Bio-Rad Quantity One 4.3.0 software.

\section{Analyzing the Catabolic Potential of the Activated Biomass}

Catabolic potential of the metagenome was analyzed from the activated biomass collected in the months of August and December by amplification of genes responsible for ring fission. Target genes chosen for amplification were $d m p \mathrm{~B}$, from the phenol degradation pathway, 
Table 2 Details of primers used in this study

\begin{tabular}{|c|c|c|c|c|c|}
\hline $\begin{array}{l}\text { S. } \\
\text { no. }\end{array}$ & Target loci & Primer sequence & $\begin{array}{l}\text { Expected } \\
\text { product } \\
\text { size }\end{array}$ & $\begin{array}{l}\text { Amplification } \\
\text { results }\end{array}$ & Reference \\
\hline 1 & $\begin{array}{l}\text { Catechol 2,3- } \\
\text { dioxygenase; } \\
(d m p \mathrm{~B})\end{array}$ & $\begin{array}{l}\text { F 5'-CGACCTGATCTCCATGACCGA-3' } \\
\text { R 5'-TCAGGTCA GCACGGTCA-3' }\end{array}$ & $238 \mathrm{bp}$ & $\mathrm{Nd}$ & {$[13]$} \\
\hline 2 & $\begin{array}{l}\text { Catechol 2,3- } \\
\text { dioxygenase; } \\
(x y l \mathrm{E})\end{array}$ & $\begin{array}{l}\text { F 5'-AGGGCCGCGTCTATCTGAAG-3' } \\
\text { R 5'-GGTCCGGGTAGTTGTAATCTCC } \\
\quad \text { AC-3' }\end{array}$ & 714 bp & $\mathrm{Nd}$ & {$[13]$} \\
\hline 3 & $\begin{array}{l}\text { Catechol 1,2- } \\
\text { dioxygenase; } \\
(p h e \mathrm{~B})\end{array}$ & $\begin{array}{l}\text { F 5'-TGGGAATTCATCACAACGACAA- } \\
\text { 3' } \\
\text { R 5'-GTGCCGGATCCCTGACTTTCTT- } \\
\text { 3' }\end{array}$ & 1004 bp & $\mathrm{Nd}$ & [13] \\
\hline 4 & $\begin{array}{l}\text { Chloro-catechol 1,2- } \\
\text { dioxygenase; } \\
(t c b \mathrm{C})\end{array}$ & $\begin{array}{l}\text { F 5'-GTITGGTACTCGAGGCCCGAIG-3' } \\
\text { R 5'-GCAAGCTTCGAAGTAG } \\
\text { TAITGTG-3' }\end{array}$ & $250 \mathrm{bp}$ & + & [13] \\
\hline 5 & $\begin{array}{l}\text { Aromatic-ring } \\
\text { hydroxylating } \\
\text { dioxygenases } \\
\text { (ARHDO) }\end{array}$ & $\begin{array}{l}\text { F 5'-GGAGACCTACAAGGGCCTGAT } \\
\text { TTTCGCCAACTGGGA-3' } \\
\text { R 5'-ACGTGCTGGATCTCGACCCA } \\
\text { GTTCTC GCCGTCGTCCTG-3' }\end{array}$ & 730 bp & + & {$[13]$} \\
\hline 6 & RAPD & $5^{\prime} \mathrm{d}[\mathrm{CCCGTCAGCA}] 3^{\prime}$ & & Fig. 1 & [14] \\
\hline 7 & 16S rRNA gene & $\begin{array}{l}\text { 27F 5'-AGAGTTTGATCMTGGCTCAG- } \\
3^{\prime} \\
\text { 1492R 5'-CGGYTACCTTGTTACGACTT } \\
-3^{\prime}\end{array}$ & $1466 \mathrm{bp}$ & $\begin{array}{l}\text { Supplementary } \\
\text { Table } 1\end{array}$ & {$[2]$} \\
\hline 8 & $\begin{array}{l}\text { DGGE with } 16 \mathrm{~S} \\
\text { rRNA gene }\end{array}$ & $\begin{array}{l}\text { 341F (5'-CCTACGGGAGGCAGCAG-3'), } \\
\text { GC-clamp (5'-CGCCCGCCGCGCGC } \\
\text { GGC GGGCGGGGCGGGGGCACG } \\
\text { GGGGG-3') attached to the 5' end } \\
\text { 534R (5'-ATTACCGCGGCTGCTGG-3') }\end{array}$ & & & {$[15]$} \\
\hline
\end{tabular}

$N d$ negative amplification results (no product observed on gel), + positive amplification product

coding for catechol 2,3-dioxygenase; $x y l \mathrm{E}$, from the xylene degradation pathway, coding for catechol 2,3-dioxygenase; phe $\mathrm{B}$, from the phenol degradation pathway, coding for catechol 1,2-dioxygenase; $t c b \mathrm{C}$, coding for chloro catechol 1,2-dioxygenase and ARHDO, aromaticring hydroxylating dioxygenases, where consensus primers constructed from gene fragments of dioxyxgenases targeting benzene derivatives [16]. Table 2 lists the primer details used in this study.

Quantitative PCR (qPCR) method was used to assess the copy numbers of target genes. One tcbC clone and one ARHDO clone was used as standard plasmid(s) to prepare a standard curve as described earlier [17]. Plasmid Standard Construction instructions by Applied Biosystems were used, which are available online at http://www.appliedbiosystems.com/ support/tutorials/pdf/quant pcr.pdf. Copies $\left(10^{1}-10^{5}\right)$ of each gene were used to create a standard curve. Real-time PCR was performed with these standard plasmids and experimental samples 1 and 5. qPCR reaction was carried out in iCycler (Bio-Rad, USA) using SYBR Green chemistry. Each $25 \mu \mathrm{l}$ reaction constituted of 50 pmol of each primer, $12.5 \mu \mathrm{l}$ of Maxima $^{\mathrm{TM}}$ SYBR Green qPCR Master Mix (biorad) which includes SYBR ${ }^{\circledR}$ Green I dye, dNTP, $\mathrm{KCl},\left(\mathrm{NH}_{4}\right)_{2} \mathrm{SO}_{4}$ and Maxima ${ }^{\mathrm{TM}}$ Hot Start Taq DNA Polymerase. Thermocycling conditions were same as regular PCR used in amplification. 


\section{Results}

All organic degradative processes at the WWT occur due to the microbial population in the activated biomass. Yet, the biomass has been considered a black-box, mostly ignored during the design and operation of the wastewater treatment process. The key to better treatment strategies lie in this black box and biologists have spent the last decade unraveling these mysteries. This study demonstrates the importance of monitoring the activated sludge and suggests parameters that need to be monitored to ensure efficient degradation of pollutants in the wastewater.

\section{Activated Sludge Parameters}

Table 1 describes the parameters maintained on-site at the treatment plant for five consecutive months. Mixed liquor suspended solids (MLSS) shows a decrease during the period of study while the hydraulic retention time (HRT) has been shown to increase from 6.4 days in the initial period of the study to 7.8 days at the end of the study. F/M ratio was being maintained at 0.1 . As can be seen from the table, the removal of COD was seen to decline indicating a fall in treatment efficiency of the CETP. To understand the fall in treatment efficiency, we analyzed the microbial community at all the five time points using simple tools.

\section{Microbial Community Shifts}

Microbial community profiles for all time points were generated by RAPD. Figure 1 demonstrates the diversity of the microbial community at five time points and shows the COD removal from the CETP. The figure shows a stable microbial community at time points 2 and 3 , but it changes at time points 4 and 5 . RAPD is a simple tool to generate unique signature patterns in the DNA. These banding patterns are not specific to a target gene but to the primer used and have been used to monitor microbial community in various niches [18]. There is a sharp decrease in COD removal in the fifth month (sample 5). This can be correlated to change in microbial community profile in samples 4 and 5. Supplementary Fig. 1 demonstrates the DGGE profile (16S) and linkage between microbial communities of all five samples. Results demonstrate two different clades, where samples 1, 2, and 3 are closely linked, while samples 4 and 5 indicate a different community profile. Bacterial taxonomy existing in the treatment plant was analyzed using culture-based and culture-independent tools at the initiation of this study (time point 1) as described in Kapley et al. [2]. The data is represented in supplementary Table S1, and accession numbers of sequences submitted in GenBank are listed in supplementary Table S2.

\section{Monitoring Catabolic Potential of the Activated Sludge}

Target genes from the central aromatic degradation pathway were selected in this study and were monitored at two time points, initial and final (1 and 5). Table 2 lists the target genes and outlines the amplification results. Only gene products of chloro-catechol 1,2-dioxygenase $(t c b C)$ and aromatic-ring hydroxylating dioxygenases (ARHDO) were amplified in this study. To confirm the amplification results, both products were cloned and random ten clones (five from biomass sample collected at time point 1 and 5 from biomass sample collected at time point 5) were sequenced. The $t c b \mathrm{C}$ clones, CCJA1-CCJA5 are the clones generated from 


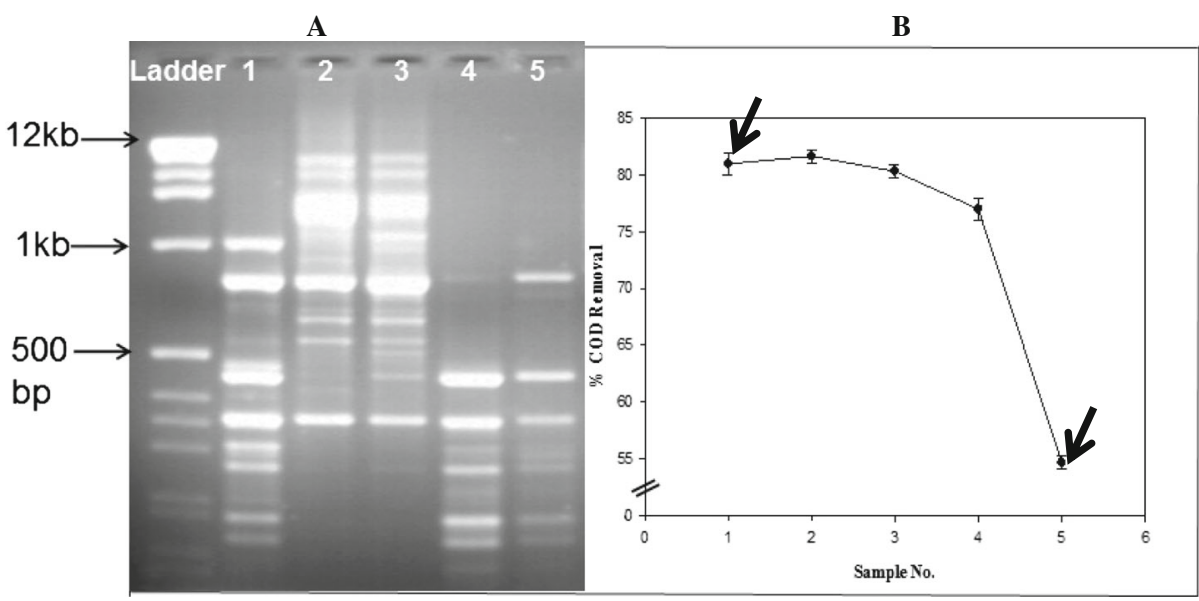

Fig. 1 Microbial community analysis and performance of the CETP. a Monitoring the microbial community of activated biomass using RAPD across 5 months, represented by numbers $1-5$. b COD of the effluent wastewater at each time point. Arrows indicate the time points when quantification of catabolic genes was carried out. The copy numbers for $t c b C$ gene in $1 \mathrm{~g}$ sludge was $1.26 \times 10^{4}( \pm 1.4)$ at time point " 1 " and $2.12 \times 10^{2}( \pm 0.82)$ at time point "5." Copy numbers of ARDHO gene in the same amount of sludge was $7.5 \times 10^{5}( \pm 1.2)$ and $3.7 \times 10^{5}$ $( \pm 0.99)$ at time points " 1 " and " 5 ," respectively

sample at time point 5 and clones CCJB1-CCJB5 are the clones generated from the activated sludge DNA at time point 1 . The sequence data of $t c b \mathrm{C}$ clones generated in this study was analyzed by BLAST and show a strong homology to chlorocatechol dioxygenase gene from different bacterial genera. Four clones demonstrated similarity index $>50$ toward the sequence of quinone oxidoreductase of Bradyrhizobium sp. ARHDO clones HDOJB1-HDOJB5 (time point 1) and clones HDOJA1-HDOJA5 (time point 5) show very strong homology to biphenyl dioxygenase genes. The accession numbers and similarity index data of these clones are listed in Tables 3 and 4.

Quantification of both target genes was also carried out at time point 1 and 5. The copy numbers for $t c b C$ gene in $1 \mathrm{~g}$ sludge was $1.26 \times 10^{4}( \pm 1.4)$ at time point " 1 " and $2.12 \times 10^{2}$ $( \pm 0.82)$ at time point " 5 ." Copy numbers of ARDHO gene in the same amount of sludge was $7.5 \times 10^{5}( \pm 1.2)$ and $3.7 \times 10^{5}( \pm 0.99)$ at time points " 1 " and " 5 ," respectively. Quantification data demonstrates that the $t c b \mathrm{C}$ gene had 100 more copies at time point 1 as compared to time point 5. This suggests a loss of catabolic capacity toward chlorinated compounds in the treatment plant with time.

\section{Discussion}

Bacterial physiology and community structure dictate the degradative capacity of the ASP, which in turn is directly related to the efficiency of wastewater treatment $[19,20]$. Hence, monitoring the microbial diversity of this niche should play a key role. While a number of methods like FISH, DGGE, T-RFLP, sequencing, etc. are reported [21], this study has used two methods to monitor community profile: RAPD and DGGE. RAPD is simple, inexpensive, and does not require highly skilled personnel as compared to the other methods and would hence be an ideal tool to use in a wastewater treatment plant. The use of RAPD is illustrated in 


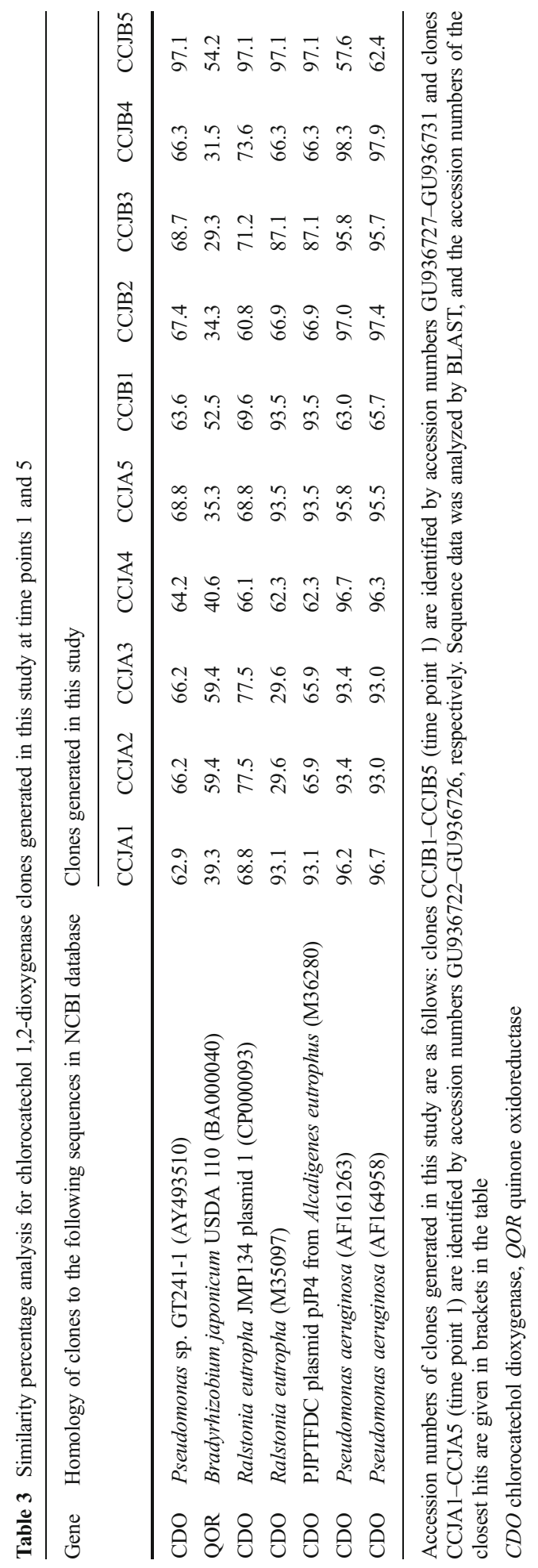




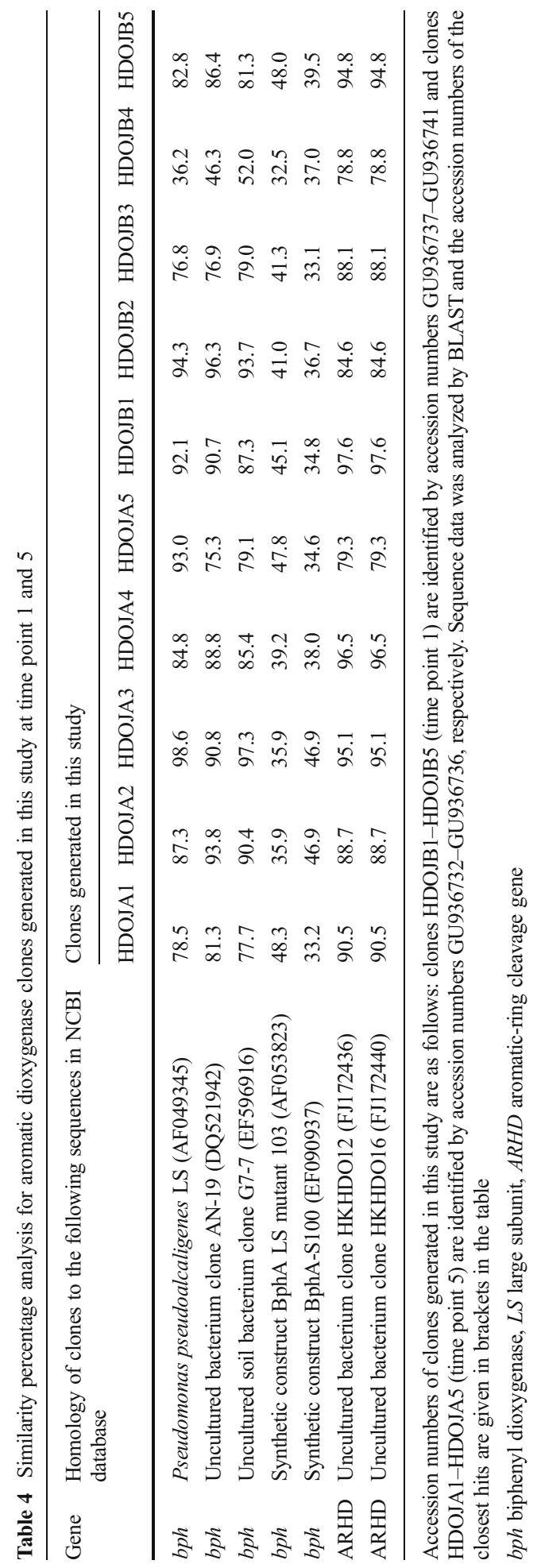


Fig. 1 where the change in microbial community is evident. The amplification pattern seen in the months of November and December (lanes 4 and 5) indicate loss in the microbial community profile and this observation corroborated with DGGE analysis. The microbial community in the months of November and December are seen on a separate clade (Supplementary Fig. S1). This change is reflected as inefficient reduction in COD removal (Fig. 1b). These observations suggest that the active population responsible for COD removal has been lost during this time period.

Aerobic degradation of aromatics is initiated by oxidation, making the compound susceptible to ring cleavage [22]. The most common route of degradation occurs via the central aromatic pathway, wherein the organic compounds are converted to catechols or substituted catechols, followed by ring fission that helps in complete mineralization [13]. For this reason, we targeted analysis of genes responsible for ring opening. Two time points were chosen for the analysis; one where the CETP was in an efficient mode of performance $(81 \%$ COD removal) and the other where it was least efficient (55\% COD removal). Results demonstrated amplification of only the $t c b \mathrm{C}$ and ARHDO gene products. Nonamplification of gene products does not necessarily mean that they do not exist. It is possible that the copy number present in the activated biomass is below detection limit. However, it also means that if the catabolic gene is present in such low numbers, it would not belong to the dominating degradation pathways occurring in the system. Hence, While amplification of target genes cannot be used to assess the presence or absence of a target genotype, it assesses the dominating catabolic genes present and thus identifies the degradative routes being followed in the treatment plant. The wastewater contains inputs from pesticide manufacturing industries and hence, genes participating in the degradation of chlorinated molecules are expected. Results of gene quantification demonstrate that the $t c b \mathrm{C}$ gene had 100 more copies at time point 1 as compared to time point 5 . This suggests a loss of catabolic capacity toward chlorinated compounds in the treatment plant with time. No significant difference in copy number was observed during quantification of the ARDHO gene, suggesting that the catabolic capacity of the activated sludge is not completely lost. Future work needs to be targeted toward recovery of the degradative capacity of the activated biomass when the system is moving toward failure. But, monitoring these changes on-site will help predict changes in the biological unit even before changes are observed in treatment efficiency. For example, in Fig. 1, a drastic change has been observed in the microbial community at time point 4 . However, the decline in COD removal was not observed until the next month (time point 5). Gene quantification data also indicated a change in the degradative genes. Being able to correlate microbial community change to degradative performance at a treatment plant would thus greatly contribute in improving efficiency of the treatment process.

The operational parameters of a WWT system also play a significant role in maintaining treatment efficiency. Figure 2 summarizes the challenges faced in the CETP to maintain an active microbial community. Firstly, the concentration of the carbon source fluctuates with the production schedule, which is dictated by the market demand and hence the composition of the wastewater cannot be kept constant. This variation will dictate the composition of the active microbial community [23-25]. Besides varying concentration of carbon source, the composition of industrial wastewater includes high salt content and high total dissolved solids (TDS) reported to interfere with the oxygen transfer necessary for biological metabolism, thereby affecting the efficiency of activated sludge process [26]. Nutrients influence the growth and survival of bacteria involved in waste degradation and also the species diversity within the sludge [27]. The nutritional balance plays a key role in catabolic capacity, where carbon/ 
nitrogen/phosphate ratios influence the degradative mode of bacteria [28, 29]. The food to microorganisms $(\mathrm{F} / \mathrm{M})$ ratio is reported to affect biomass growth and activity, and the ratios need to be maintained as per specific activity of the treatment plant [30]. At this CETP, the F/M ratio has been maintained at a constant of 0.1. During the logarithmic growth phase, there is a high $\mathrm{F} / \mathrm{M}$ ratio, greater than 1 . As the microorganisms continue utilizing the food supply, a point is reached where the amount of food remaining limits the growth rate of the microorganisms (stationary phase). At this point, the F/M is exactly equal to 1 . The growth rate of the microorganisms as well as their oxygen utilization begins to taper off. When the amount of food used in producing energy and forming end products is greater than the amount used in forming new cellular material, it is the ideal scenario for a wastewater treatment system and the $\mathrm{F} / \mathrm{M}$ ratio is much less than 1 . The ratio being maintained at this CETP suggests the degradative mode of the activated biomass.

We have previously demonstrated the role of dissolved oxygen (DO) levels in wastewater treatment efficiency [31]. Since the CETP is an aerobic system, the levels of oxygen (DO) also control the degradative capacity of the bacterial community [32]. The treatment efficiency is also dependent on HRT that varies as per the organic load [33, 34]. The performance of the bacterial community in this complex niche is thus governed by a spectrum of interrelated parameters, viz., organic loadings, nutritional levels, F/M ratios, DO levels, and redox [35, 36]. By monitoring the parameters outlined in Fig. 2, WWT personnel can help maintain the degradative mode of the activated sludge.

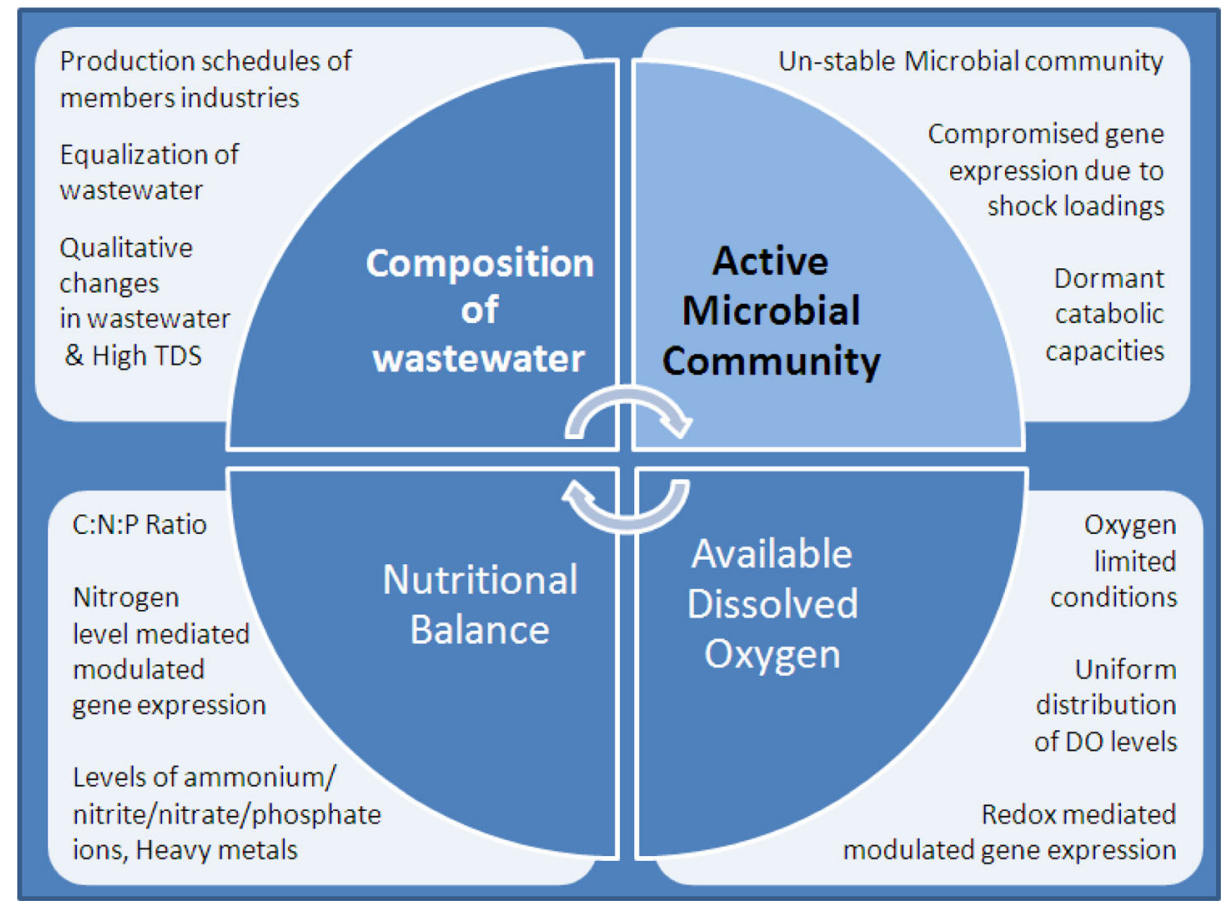

Fig. 2 Parameters influencing the microbial community in a CETP that control the expression of the microbial capacities. The active microbial community is influenced by the parameters represented in the circle, i.e., composition of wastewater, nutritional balance and DO levels. Each of these is, in turn, influenced by a large number of factors that are listed outside the circle 


\section{Conclusion}

The activated sludge process has worldwide application and the last decade has been spent in understanding the mysteries of the microbial population of this niche. The goal is to understand the biological interface that carries out the degradation in a WWT. This study demonstrates that the microbial population can be monitored using simple genomic tools like RAPD or DGGE, and this change, supplemented by gene quantification data, helps in understanding the degradative health of the activated sludge.

Any WWT system is subject to a number of variable parameters (influent, $\mathrm{pH}$, temperature due to seasonal variations, $\mathrm{C} / \mathrm{N} / \mathrm{P}$ ratios, etc). Future work needs to be undertaken to use simple genomic tools to assess the activated biomass at different time points, relate it to operational parameters and develop a control system using fuzzy logic that can define the best conditions to bring about maximum degradative capacity of the biomass, thus improving wastewater treatment efficiency.

Acknowledgments The authors are grateful to the CSIR-NEERI network project, MESER-ESC0108, for supporting this work. The authors thank the CETP management for providing data and activated sludge samples. Part of this work was carried out at the State Key Lab of Environmental Aquatic Chemistry, Research Center for Eco-Environmental Sciences, Chinese Academy of Sciences, Beijing, China.

\section{References}

1. Liu, X. C., Zhang, Y., Min, Y., Wang, Z. Y., \& Lv, W. Z. (2007). Analysis of bacterial community structures in two sewage treatment plants with different sludge properties and treatment performance by nested PCRDGGE method. Journal of Environmental Sciences, 19, 60-66.

2. Kapley, A., De Baere, T., \& Purohit, H. J. (2007). Eubacterial diversity of activated biomass from a common effluent treatment plant. Research in Microbiology, 58, 494-500.

3. Sengupta, B. (2005). http://cpcb.nic.in/upload/Publications/Publication_24_ PerformanceStatusOfCETPslinIndia.pdf. Accessed 1 March 2015.

4. Lei, G., Ren, H., Ding, L., Wang, F., \& Zhang, X. (2010). A full-scale biological treatment system application in the treated wastewater of pharmaceutical industrial park. Bioresource Technology, 101, 5852-5861.

5. Muthu, C., \& Agamuthu, P. (2004). Centralized wastewater treatment. Malaysian Journal of Science, 23, 89-101.

6. Engin, G. O., \& Demir, I. (2006). Cost analysis of alternative methods for wastewater handling in small communities. Journal of Environmental Management, 79, 357-363.

7. Nesaratnam, S. T., \& Ghobrial, F. H. (1985). Biological treatment of mixed industrial and sanitary wastewaters. Conservation and Recycling, 8, 135-142.

8. Lovley, D. R. (2003). Cleaning up with genomics: applying molecular biology to bioremediation. Nature Reviews Microbiology, 1, 35-44.

9. Wagner, M., Loy, A., Nogueira, R., Purkhold, U., Lee, N., \& Daims, H. (2002). Microbial community composition and function in wastewater treatment plants. Antonie Van Leeuwenhoek, 81, 665-680.

10. Kapley, A., Prasad, S., \& Purohit, H. J. (2007). Changes in microbial diversity in fed-batch reactor operation with wastewater containing nitroaromatic residues. Bioresource Technology, 98, 2479-2484.

11. Porwal, S., Lal, S., Cheema, S., \& Kalia, V. C. (2009). Phylogeny in aid of the present and novel microbial lineages: diversity in Bacillus. PLoS One, 4, e4438.

12. Khardenavis, A. A., Kapley, A., \& Purohit, H. J. (2010). Salicylic-acid-mediated enhanced biological treatment of wastewater. Applied Biochemistry and Biotechnology, 160(3), 704-718.

13. Kapley, A., \& Purohit, H. J. (2009). Diagnosis of treatment efficiency in industrial wastewater treatment plants: a case study at a refinery ETP. Environmental Science and Technology, 43, 3789-3795.

14. Purohit, H. J., Kapley, A., Moharikar, A., \& Narde, G. (2003). A novel approach for extraction of PCRcompatible DNA from activated sludge samples collected from different biological effluent treatment plants. Journal of Microbiological Methods, 52, 315-323. 
15. Muyzer, G., De Waal, E. C., \& Uitterlinden, A. G. (1993). Profiling of complex microbial populations by denaturing gradient gel electrophoresis analysis of polymerase chain reaction-amplified genes coding for $16 \mathrm{~S}$ rRNA. Applied and Environmental Microbiology, 59, 695-700.

16. Kahl, S., \& Hofer, B. (2003). A genetic system for the rapid isolation of aromatic-ring-hydroxylating dioxygenase activities. Microbiology, 149, 1475-1481.

17. Sagarkar, S., Mukherjee, S., Nousiainen, A., Björklöf, K., Purohit, H. J., Jørgensen, K. S., \& Kapley, A. (2013). Monitoring bioremediation of atrazine in soil microcosms using molecular tools. Environmental Pollution, 172, 108-115.

18. He, Z., Zhao, J., Gao, F., Hu, Y., \& Qiu, G. (2010). Monitoring bacterial community shifts in bioleaching of $\mathrm{Ni}-\mathrm{Cu}$ sulfide. Bioresource Technology, 101, 8287-8293.

19. Wittebolle, L., Boon, N., Vanparys, B., Heylen, K., De Vos, P., \& Verstraete, W. (2005). Failure of the ammonia oxidation process in two pharmaceutical wastewater treatment plants is linked to shifts in the bacterial communities. Journal of Applied Microbiology, 99, 997-1006.

20. Liu, G., \& Wang, J. (2013). Long-term low DO enriches and shifts nitrifier community in activated sludge. Environmental Science and Technology, 47, 5109-5117.

21. Hu, M., Wang, X., Wen, X., \& Xia, Y. (2012). Microbial community structures in different wastewater treatment plants as revealed by 454-pyrosequencing analysis. Bioresource Technology, 117, 72-79.

22. Phale, P. S., Basu, A., Majhi, P. D., Devecryshetty, J., Vamsee-Krishna, C., \& Shrivastava, R. (2007). Metabolic diversity in bacterial degradation of aromatic compounds. OMICS, 11, 252-279.

23. Figuerola, E. L., \& Erijman, L. (2007). Bacterial taxa abundance pattern in an industrial wastewater treatment system determined by the full rRNA cycle approach. Environmental Microbiology, 9, 1780-1789.

24. Lv, X.M., Shao, M.F., Li, J., Li, C.L. (2015). Metagenomic analysis of the sludge microbial community in a lab-scale denitrifying phosphorus removal reactor. Applied Biochemistry and Biotechnology, 1-13.

25. Ibarbalz, F. M., Figuerola, E. L., \& Erijman, L. (2013). Industrial activated sludge exhibit unique bacterial community composition at high taxonomic ranks. Water Research, 47, 3854-3864.

26. Pophali, G. R., Kaul, S. N., \& Mathur, S. (2003). Influence of hydraulic shock loads and TDS on the performance of large-scale CETPs treating textile effluents in India. Water Research, 37, 353-361.

27. Burgess, J. E., Quarmby, J., \& Stephenson, T. (1999). Role of micronutrients in activated sludge-based biotreatment of industrial effluents. Biotechnology Advances, 17, 49-70.

28. Leys, N. M., Bastiaens, L., Verstraete, W., \& Springael, D. (2005). Influence of the carbon/nitrogen/ phosphorus ratio on polycyclic aromatic hydrocarbon degradation by Mycobacterium and Sphingomonas in soil. Applied Microbiology and Biotechnology, 66, 726-736.

29. Wu, B., Yi, S., \& Fane, A. G. (2012). Effect of substrate composition (C/N/P ratio) on microbial community and membrane fouling tendency of biomass in membrane bioreactors. Separation Science and Technology, $47,440-445$.

30. Villain, M., \& Marrot, B. (2013). Influence of sludge retention time at constant food to microorganisms ratio on membrane bioreactor performances under stable and unstable state conditions. Bioresource Technology, $128,134-144$.

31. Yadav, T. C., Khardenavis, A. A., \& Kapley, A. (2014). Shifts in microbial community in response to dissolved oxygen levels in activated sludge. Bioresource Technology, 165, 257-264.

32. Kapley, A., Tolmare, A., \& Purohit, H. J. (2001). Role of oxygen in the utilization of phenol by Pseudomonas CF600 in continuous culture. World Journal of Microbiology and Biotechnology, 17, 801804.

33. Huang, Z., Ong, S. L., \& Ng, H. Y. (2011). Submerged anaerobic membrane bioreactor for low-strength wastewater treatment: effect of HRT and SRT on treatment performance and membrane fouling. Water Research, 45, 705-713.

34. Kim, M., Guerra, P., Theocharides, M., Barclay, K., Smyth, S. A., \& Alaee, M. (2013). Parameters affecting the occurrence and removal of polybrominated diphenyl ethers in twenty Canadian wastewater treatment plants. Water Research, 47, 2213-2221.

35. Diez, M. C., Castillo, G., Aguilar, L., Vidal, G., \& Mora, M. L. (2002). Operational factors and nutrient effects on activated sludge treatment of Pinus radiata kraft mill wastewater. Bioresource Technology, 83, 131-138.

36. Tanwar, P., Nandy, T., Ukey, P., \& Manekar, P. (2008). Correlating on-line monitoring parameters, pH, DO and ORP with nutrient removal in an intermittent cyclic process bioreactor system. Bioresource Technology, 99, 7630-7765. 